\title{
LIFE HISTORIES OF NORTH AMERICAN GEOMETRIDAE-LXIII.
}

\author{
BY HARRISON G. DYAR, WASHINGTON, D. C.
}

Sciagraphia neptata Guenće.

Egg. Elliptical, very strongly flattened, concave, slightly wedge-shaped in side view, the ends rounder; evenly reticulate in broad, rounded ridges, wavy, stellate hexagonal, rather smaller on the flat sides. Dark bluish green, turning, red around the margin. Size $.8 \times .5 \times \cdot 3 \mathrm{~mm}$.

Slage $I$. Head rounded, brownish luteous, sutures darker. Body moderate, rather short, luteous, dark olive green shaded broadly over the dorsum except on joints 2 and 13 posteriorly : venter faintly dark shaded. No shields; tubercles and setae obscure, tubercles slightly elevated, but concolorous, setae stout, pale, quite small, enlarged at tip.

Stage 11 . Head luteous, slightly bilobed; width $.5 \mathrm{~mm}$. Body moderate grayish green with broad ventral purple brown stripe and faint, narrow, pale lines, two showing in the subdorsal region. Feet dark within: tubercles and setae obsolete.

Stage III. Head round, full, flattish before, greenish white with a straight brown mottling on the sides; width $.9 \mathrm{~mm}$. Body moderate, green, the dorsum with five parallel olivaceous blackish bands as wide as the interspaces;.venter broadly smoky blackish. No shields; thoracic feet shaded darker; abdominal ones pale without; tubercles minute, setae fine, dark.

Stage $I V$. Head bilobed, oblique, pale greenish luteous with whitish shades, a brown flush on the sides, the angle below the eyes and antennae whitish; width $\mathbf{1 . 5} \mathrm{mm}$. Body uniform, rather flattened, anal feet large; obscure whitish, not strongly greèn, a broad subdorsal geminate band more whitish; stigmatal fold pale yellow; a ventral vinous brown shade staining the bases of the feet. T' bercles obsolete, setae fine, dark, obscure. A subventral dark spot on joint 6 .

Stage $V$. Head bilobed, thicker at apex, pale brown shaded, a curved dark brown band across above clypeus and a yellow one on the side behind the eyes; width $2.2 \mathrm{~mm}$. Body moderate, uniform, a somewhat raised black patch subventrally on joint 6 . All yellow brown shaded; dorsal, subdorsal, lateral, subventral geminate blackish lines, broken, powdery, the dorsal appearing as intersegmental spots, the others broken intersegmentally, giving an effect of obscure segmentary transverse bands on central part of body. Dark blotches at the bases of the thoracic feet, especially on joint 4 ; tubercles small, dark, setae dusky, 
rather long, fine; feet pale; spiracles black edged.

The larvae fed on the balsam poplar (Populus baslamea); eggs from Kaslo, British Columbia July 27, mature larva in September. The species is double brooded with hibernation in the pupal stage. 

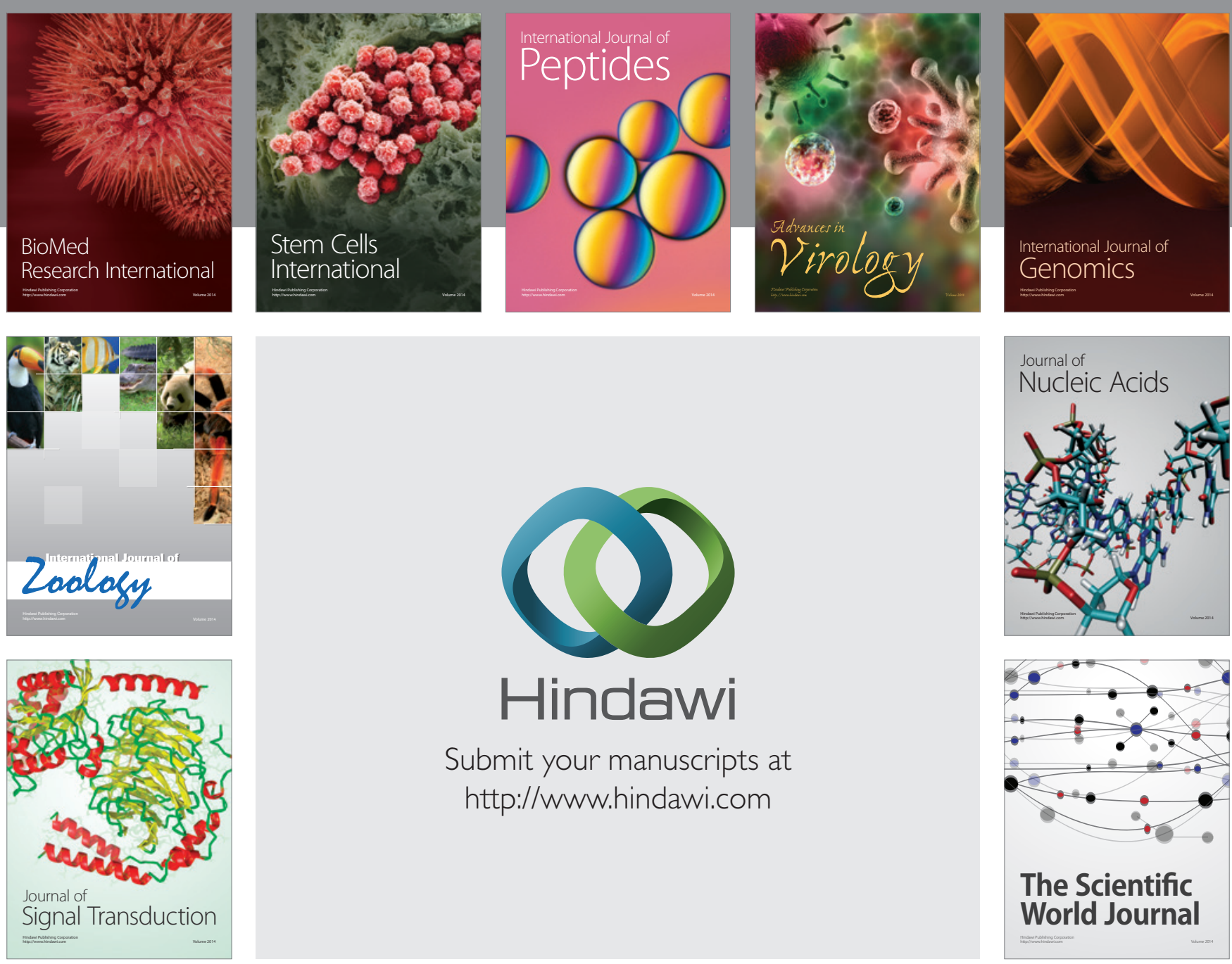

Submit your manuscripts at

http://www.hindawi.com
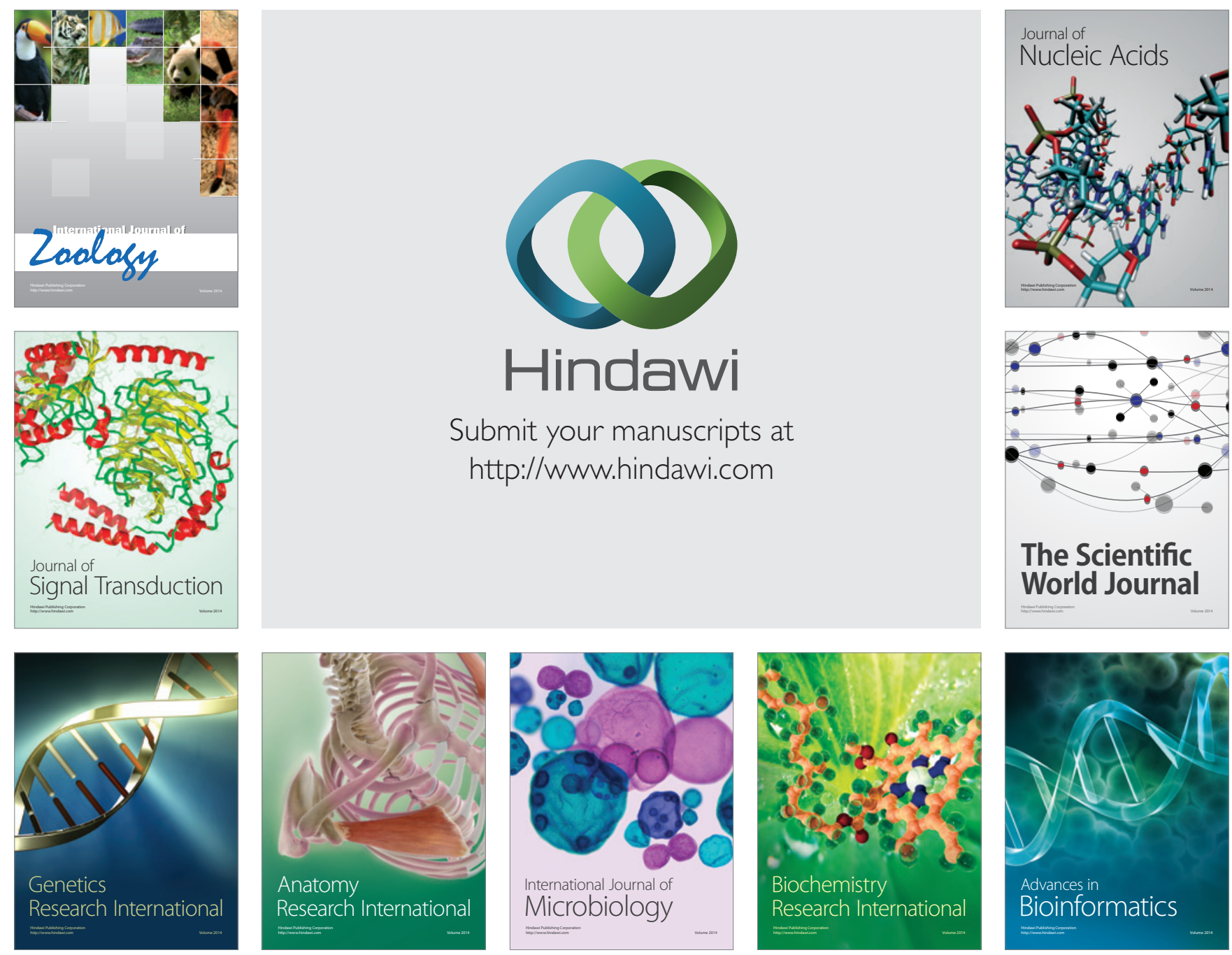

The Scientific World Journal
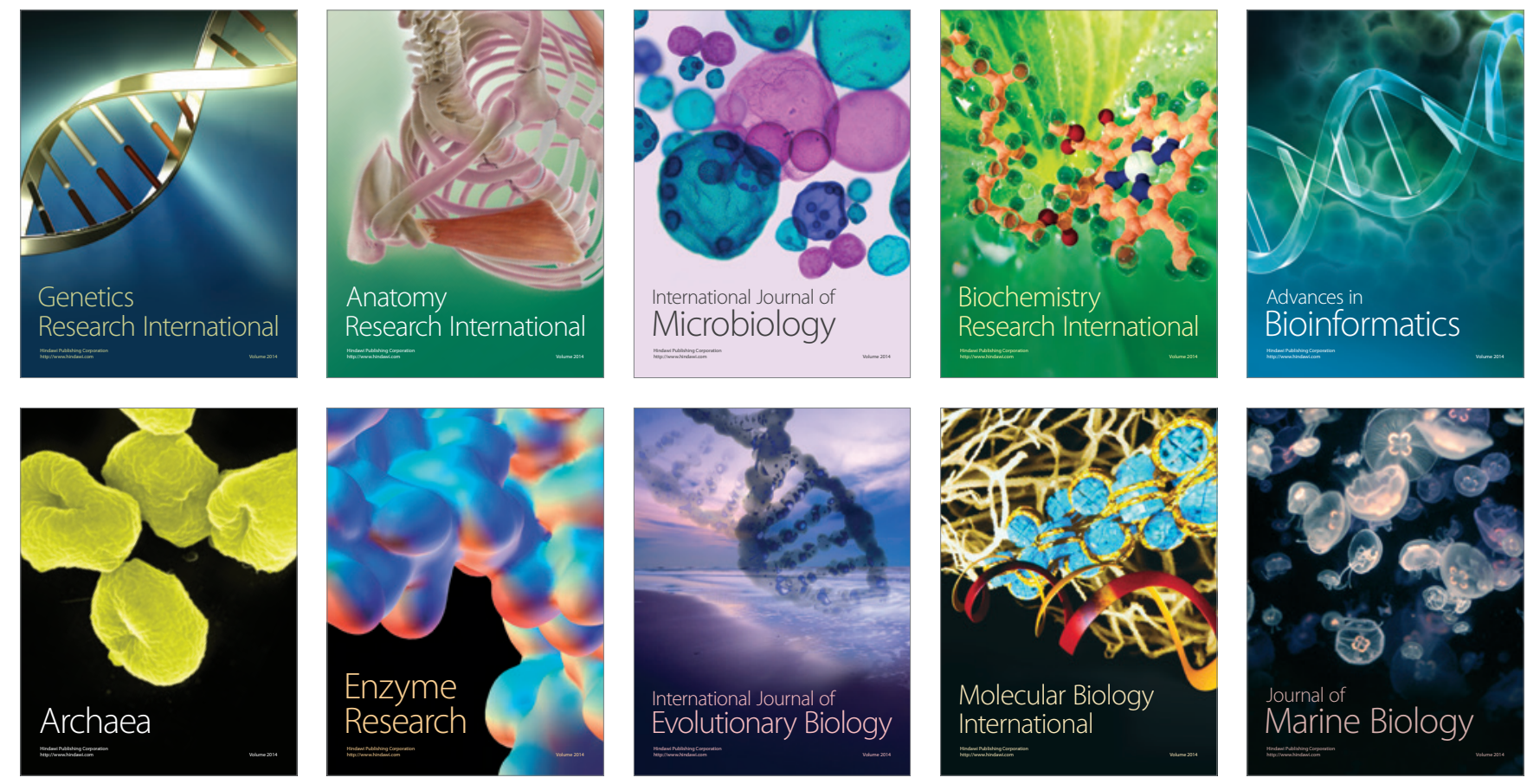